\title{
Transsexualism and sex reassignment surgery - Arising medicolegal issues
}

\author{
Richa Gupta ${ }^{1}$, Sangeeta Sahu ${ }^{2}$, Ankush Gupta ${ }^{3}$, Tarun Singh ${ }^{4, *}$ \\ ${ }^{1,2,3}$ Assistant Professor, ${ }^{4}$ Tutor, Dept. of Forensic Medicine and Toxicology, SN Medical College, Agra, Uttar Pradesh
}

*Corresponding Author:

Email: tarunsingh611@gmail.com

\begin{abstract}
Introduction: Transgender community in India has been facing challenges in various issues since ages. They are debarred from their rights related to marriage and child adoption. Pertaining to rights related to inheritance, wills and trusts, employment, access to Government, public and private health care services, and use of social welfare and health insurance schemes, they are far behind. The recent advances in the field of medicine have made the treating physicians belief that after careful selection of the patients based on standard criteria, the gender identity disorder or transsexualism can be diagnosed and successfully treated by reassignment surgery, which in turn created, a new gender. This new gender, has further led to many legal complications for postoperative transsexuals in our country.

Materials and Methods: Desk review and qualitative data were consummated for the purpose of this study.

Result and Conclusion: This article examines transsexualism in purview of the historical perspective and its genesis factors, and also draws attention to medico-legal considerations arising of Sex reassignment surgery.
\end{abstract}

Keywords: Transsexualism, Transgender (TG), Gender affirmation surgery (GAS), Sex reassignment surgery (SRS), Intersex.

\section{Introduction}

Transgender (TG) people in India face a variety of issues. ${ }^{1,2}$ So far, the TG communities have been excluded from effectively participating in all social and cultural activities. They don't have any legal status in economic and political decision-making processes.

A primary reason of the exclusion can be probably the lack of (or ambiguity in) legal recognition of identity of trans sexual persons. The legal ambiguity of their gender status is a key barrier that often prevent them in exercising their rights related to marriage with a person of their desired gender, child adoption, inheritance, wills and trusts, employment, and access to public and private health services, and access to and use of social welfare and health insurance schemes.

Legal recognition of the gender status of $\mathrm{TG}$ people is also critical for their right to contest and right to vote in the elections. The Election Commission has introduced the option of 'other' in the voter's identity card and indicated that transgender people can vote or contest as 'other'. ${ }^{3,4}$ However, the legal validity of this executive order on the right to contest is not apparently clear.

Another key legal issue is the ambiguous legal status of the sex reassignment surgery (SRS) itself and the legal validity of the post-operation certificate provided by the health care providers about the current sex of the transgender person as there are no explicit policy or legal guidelines on the same from the government. ${ }^{5}$

Historical Perspective: The prevalence of transsexualism in the Netherlands is estimated to be 1:11900 males and 1:30400 females. ${ }^{6}$ In Sweden, it is 1:37000 among males and 1:30000 in females. The estimates for USA are 1:100000 for males and 1:400000 for females.
Indian mythology has in it, many references to altered sexual states. Even the ancient mythological books mention the name of Ardhanarishwara ${ }^{1-3}$ referred to as God, who is half man and half woman, worshipped as an androgynous deity. In various versions of Ramayana and in Mahabharata, there have been references of persons spending their life in intersexed condition. ${ }^{4,7}$

Sex, Gender and Transsexualism: To understand transsexualism, we need to understand the difference between sex and gender. The word 'Sex' represents physical differentiation as male or female, indicated by the external anatomy of genitalia, the presence or absence of gonads and chromosomal analysis. 'Gender' denotes the psychological recognition of self, its sexual inclination towards desired gender and wish to be considered by others, as fitting into one of the social categories such as boy/man or girl/woman. In short, sex is what one is seen as (external appearance as male/ female) and gender being the identity is what one feels (playing the role of and living the life of male/ female). ${ }^{9}$ The feeling of an in congruency between one's sex and gender is termed gender dysphoria. Transsexualism is the most extreme form of this disorder. These individuals feel themselves to be trapped in the wrong body (transsexual phenomenon). They need to adapt their phenotype with hormones and surgery to make it congruent with their gender identity. ${ }^{8}$ There are many terminologies coined for sex change surgery, such as sex reassignment surgery, gender reassignment surgery, sex reconstruction surgery, sex affirmation surgery, feminizing or masculanizing genitoplasty. There is a broad feeling that gender, as its one's own inclination, is not a subject to reassignment. It can at best be affirmed by bringing the external appearance (sex) of the person to become congruent with his/her gender. ${ }^{11}$ 
Thus, the most appropriate term may be gender affirmation surgery (GAS), but still Sex reassignment surgery (SRS) is the more commonly used term. Transsexuals those undergoing female to male (FTM) transition are known as Transmen and those undergoing male to female (MTF) transition are known as Transwomen.

\section{Genesis of Transsexualism}

The following explanations are often forwarded:

Psychological Explanations: Many stress the importance of an unhappy childhood in preventing normal psychosexual development. The terms, psychologic conditioning and faulty identification are often used in this regard.

Some of the main explanations based on this reasoning are:

1. Parental rejection due to the parents having wanted a child of the opposite sex may cause the child to become prematurely occupied with the idea of masculinity and femininity, unsure of itself and regarding its genitals as the reason for its rejection.

2. Dressing the child in the clothes of the opposite sex, at least off and on until the age of three or four, may affect a boy's conception of, and identification with, his own sex.

3. Reversal in parental role. For example, the male transvestite may have a domineering, aggressive, overprotective mother and an inadequate father figure, either because the father has a weak, colourless nature, or because the family lacks a father. This may cause a compensatory, overmasculine attitude to militate against difficulty in identification and a feeling of inadequate masculinity. An enhanced identification with the parent of the opposite sex, or an inadequate identification with the parent of the same sex has also been reported to be responsible for the anomaly (Taylor, 1964).

4. A change in body image, for instance, through endocrine disorder, might tend to change the psychosexual behaviour, partly through the subject's own reaction to the change in their own anatomy and partly through the reactions of others.

Organic explanations include:

Genetic Factors: Barr and Bertram's discovery of sex chromatin led to many studies of chromosomal sex in transsexuals. Dowling and Knox (1963), reported male transsexuals with positive sex chromatin. Physical abnormalities like a scanty beard, high pitched voice, testicular hypoplasia and feminine build in the males and the virilism and poorly developed breasts in the females point to a constitutional origin of transsexualism.

Hormones: Different cases of transsexualism and an estrogen producing tumour of the adrenal glands in which the transsexualism diminished after the tumour was removed surgically. There are reported cases of an androgen-producing testicular tumour combined with transsexualism.

Cerebral Lesion: Cases of cerebral lesion associated with transsexualism and transvestism were described as far back as 1869. Some studies have pointed out that the anomaly might be derived from anomalies in the cerebral organization, while others suggested that a cerebral disorder of biochemical nature might be at fault. Cases of epilepsy among persons with this psychosexual anomaly provide more concrete evidence of the possibility of a cerebral lesion (Pennington, 1960).

Multifactorial Theories: Some authors, especially those with first-hand knowledge of a large number of cases, are inclined to believe that the anomaly is due to a combination of constitutional, psychological and hormonal factors. Many theories have been put forward to explain the syndrome. They include genetic or hormonal influences, psychosocial problems, social learning theories, and psychoanalytical theories. But the very existence of so many theories exemplifies that the genesis of the syndrome is not properly understood.

\section{Management}

The transsexualism is now supposed to be as a curable and treatable disease with the collaboration of behavioural, endocrinological, and surgical specialists working as a team. The usual protocol for the management of a transsexual condition is hormone therapy, followed by, or simultaneously with, facial hair electrolysis and Reassignment surgery. Studies have shown that many transsexuals have benefited from such reassignment surgery, if patients properly selected and carefully managed. ${ }^{8}$

\section{Materials and Methods}

A comprehensive literature review was conducted to document the current legal recognition of transgender people in India. We studied and carried indepth interviews of the transgender cases and post operative transsexual cases coming here for medicolegal purposes, health care providers and lawyers. Desk review and qualitative data were consummated for the purpose of this study.

\section{Results}

The transgender cases coming here were usually for gender determination for reasons of contesting in elections, or victims of sexual offences or fraud in sex reassignment surgery. We found gross lack of legal documentation in support of SRS on part of the treating surgeon's team. In establishing gender identity of a person following differential diagnosis should be kept in mind.

\section{Differential diagnosis for the condition may be-}

1. Classic trans-sexual.

2. Gender dysphoria syndrome, (formerly effeminate homosexuality) 
3. Gender dysphoria syndrome, (formerly transvestitism)

4. Gender dysphoria syndrome, psychosis.

5. Gender dysphoria syndrome, psycho -neurotic sociopathy.

6. Gender dysphoria syndrome, inadequate and schizoid personality

Only Classic transsexuals are considered for 'others' category. These 'Classic Transsexual', he/she may also be treated with SRS guided by standard protocol. $^{13}$

Before undertaking a SRS, a firm diagnosis for the transsexual condition must be established. The criteria for these are: ${ }^{7,13}$

1. A sense of discomfort and inappropriateness about one's sex.

2. A wish to be rid of one's genitalia and the desire to live life as a member of the opposite sex.

3. This discomfort/disturbance has been continuously present for a minimum of 2 years and is not limited to a period of stress.

4. An absence of physical intersex or genetic abnormality.

5. Absence of a mental disorder such as schizophrenia.

Before undergoing SRS, referral letters from mental health professionals are essentially required mentioning the following points:

1. A description of patient's general identifying characteristics.

2. Initial and evolving gender, sexual and other psychiatric diagnoses.

3. Duration of professional relationship with the patient, number of consults, the type of psychotherapy or evaluation that the patient underwent.

4. Specifying the eligibility criteria that have been met and the rationale for prescribing hormone therapy or surgery.

5. Degree to which the patient has followed the Standards of care till the time of writing, and the likelihood of future compliance.

6. Whether the mental health professional is part of a gender team.

7. That the mental health professional would like to receive a phone call from the gender team confirming the authenticity of this letter.

The above letter should be addressed to the physician who will be responsible for the patient's medical treatment, and is sufficient for instituting hormone therapy or for a referral for breast surgery (e.g., mastectomy, chest reconstruction, or augmentation mammoplasty).

Letters from two mental health professionals are required before operating any Genital Surgery which includes- a. Genital surgery for male to female transsexuals orchiectomy, penectomy, clitoroplasty, labiaplasty or creation of a neovagina.

b. Genital surgery for female to male transsexuals hysterectomy, salpingo -oophorectomy, vaginectomy, metoidioplasty, scrotoplasty, urethroplasty, placement of testicular prostheses or creation of a neophallus.

An appropriate period of hormone therapy, is usually 6 months. Trans-sex hormonal treatments are important for a smooth gender transition, both physically and psychologically in selected individuals with gender identity disorders. In the absence of indigenous source, hormone therapy is medically necessary for a satisfying role in the patient's new sex. When physicians administer androgens to biologic females and estrogens, progesterone, and testosterone blocking agents to biologic males, patients feel and appear more like members of their preferred sex. Before starting administration of hormone therapy, following criteria should be met -

1. Patients age must be 18 years or above.

2. In depth knowledge of what hormones can achieve medically, their social benefits and risks.

3. A documented real - life experience of at least 3 months prior to the administration of hormones.

A period of psychotherapy of a duration specified by the mental health professional after the initial evaluation (usually a minimum of 3 months) should be given.

Consent Forms: Consent form is the most essential legal document before administering hormone therapy or any surgical correction. It is advisable to convert the consent and waiver of liability form (written below) into affidavits by paying the Notary or Court Fee and getting the counter signatures of a Notary or Magistrate, respectively. ${ }^{15}$ This means that now the state is taken as a witness.

1. Procedure - specific consent form: It includes a description of the surgical procedure. It also mentions the surgical and anaesthetic complications that may occur. This also includes an estimate of the procedure.

2. Waiver of Liability Form [Form 1]: It contains a waiver of liability from the change in sexual appearance, long term use of hormones and permanent, irreversible change in current sexual functioning. ${ }^{17,18}$

\section{Form 1. Example of an informed consent and waiver of liability form used by a SRS provider Informed consent and waiver of liability}

I, ---------, having been fully informed in writing of the potential risks and complications of hormonal or surgical sex reassignment, do hereby choose of my own free will and consent to undertake this treatment because I want to alter my physical appearance to more closely reflect my gender identity. 
I hereby release Dr. of any and all liability for my decision to undertake a change of my sexual appearance and, long-term use of hormones or for sex reassignment surgery to effect on a permanent, irreversible basis my current sexual functioning.

I promise not to sue Dr. ---------------------- for any of the consequences of my hormonal or surgical sex reassignment unless those consequences are the result of negligence in the conduct of my hormone therapy or in the carrying out of my surgery.

Dated, signed and witnessed.

All SRS providers do not issue a post-SRS medical certificate, unless they are specifically asked by the patients.

\section{Form 2. Example of a post-SRS medical certificate} issues by a SRS provider

This is to certify that Mr. XXX [male name], now called as YYY [female name], a transgender; physically a male and psychologically a female has had Sex Reassignment Surgery on (DD/MM/YYYY), after undergoing all investigations and psycho-legal counselling.

Date of Birth in record: DD/MM/YY

\section{Conclusions}

An Indian surgeons team dealing with Transsexual patients is faced with a number of problems. Though SRS has been legally allowed in U.K. since 1967, in U.S.A. since 1972, and in various other countries, Indian Laws are silent on this issue. In India, there is no law that authorizes sex change operation nor has any legal precedent been developed. But, increasing incidences of transgender recognition and SRS associated with it are seen, and consequently are arising legal issues in concern to it. SRS involves changes in gender identity and sex of the person. Consequently, the existing laws in their present form are falling short off when dealing with the rights pertaining to the transsexuals. Following laws are required to be reviewed in concern to rights of transsexuals. ${ }^{19}$

\section{The Penal Code 1860:}

1. The definition of 'rape' may require a change.

2. Section 377 IPC, dealing with unnatural offence.

3. The definitions of 'wife', 'husband', 'adultery', as incorporated in Sections 497, 498 and 498A IPC.

4. The definitions of 'wife' as contemplated in Section $125 \mathrm{CrPC}$ and Laws regarding maintenance.

\section{Personal Laws:}

1. Hindu Marriage Act and all personal Laws related to marriage. The present laws will fall shortly inadequate in questions of maintenance, grounds for divorce and custody of children.

2. Hindu Adoptions and Maintenance Act 1956.

3. Hindu Succession Act, especially Sections 8, 14 and 23 .
4. Labour and Industrial Laws, especially Workmen's Compensation Act 1923, Factories Act 1948 and reservation of jobs on the basis of sex.

Taxing Statutes: Various beneficial provisions like tax exemptions available only to women, under the Income Tax Act.

Another aspect is the consent for the procedure and safe guarding the surgeon or the gender team from future litigation. Though waiver of liability and consent forms are available, there is an absence of legal back up. In view of this situation, it is better to convert these consent forms into affidavits by getting these signed by a magistrate or notary. ${ }^{12}$ On completion of SRS, a postSRS medical certificate should be issued to the patient by the gender team consisting of the operating surgeon, psychiatrist and endocrinologist.

There is also the issue of postoperative sexual and legal status of the patient. Present Indian Laws concerning to marriage, adultery, sexual offences, unnatural offences, adoptions, maintenance, succession, labour and industrial laws will require modifications when dealing with these individuals and protecting their rights. The patient also faces difficulties during change in name, birth certificates, school and college certificates, identity cards and passports postoperatively. Abroad, a new concept is arising, of unisex identity cards by eliminating reference to person's sex in these documents but, in India, however, the battle will be a long run.

The issue of transsexualism and sex reassignment surgery is very vast and has many angles. This is a short or maiden attempt to study the legal consequences arising from transgender recognition and postoperatively arising legal issues. It has to be always kept in mind that the persons who have undergone such sex change operation remain human beings even after such operation and thus the fundamental rights as guaranteed by our constitution should be available to them. We have tried to identify few medical, legal and legislative challenges presently faced by the medicolegal expert, plastic surgeon and his gender reassignment team, in dealing with the issues concerning transsexuals.

\section{Acknowledgments}

Authors wish to sincerely thank all my patients and other health care providers whose patience and cooperation have made this work possible.

\section{References}

1. Elephanta Caves [Internet] From Wikipedia, the free encyclopedia. Available from:

http://en.wikipedia.org/wiki/Elephanta_Caves [cited 2008 Sep 26]

2. Shikhandi [Internet] From Wikipedia, the free encyclopedia. Available from: http://en.wikipedia.org/wiki/Shikhandi [cited 2008 Sep 25] Research for Sex Work. p.12-14.

3. Http://timesofindia.indiatimes.com/india/Undertrialsmust-get-right-to-vote-Election-

Commission/articleshow/5259200.cms 
4. Http://www.queerty.com/india-asks-voters-male-femaleor-transgender-2009 1113/ Timeline - Transgender History [Internet] Transgender Health U.K. Social Resources. Available from:

http://www.transgenderzone.com/features/timeline.htm [c ited 2009 Apr 28]

5. Kalkinath Ardhanarishwara - the god who is half woman [Internet] U.K. Available

from:http://philhine.org.uk/writings/tt_ardhanarishvara.ht $\mathrm{ml}$ [cited 2008 Sep 25]

6. Lawrence A, editor. World Professional Association for Transgender Health. The Harry Benjamin International Gender Dysphoria Association's Standards of Care for Gender Identity Disorders, Sixth Version. [Internet] Available from: http://wpath.org/Documents2/socv6.pdf [cited 2009 Apr16]

7. Ardhanari [Internet] From Wikipedia, the free encyclopedia. Available from: http://en.wikipedia.org/wiki/Ardhanarishvara [cited 2008 Sep 25]

8. Phillip S., Michael J.T. and Russell R. (1993) Sex reassignment surgery. A study of 141 Dutch transsexuals. Brit J Pschiatry. 162, 681-5.

9. Billy Tipton [Internet] From Wikipedia, the free encyclopedia. Available from: http://en.wikipedia.org/wiki/Billy_Tipton [cited 2009 May 21]

10. Ahuja RB, Bhattacharya S. Intersex, Transsexuality and Gender Reassignment Surgery. Indian J Plast Surg. 2001;34:83.

11. Asscheman H, Diamond M, Ceglie DD, Kruijver F, Martin J, Playdon ZJ, et al. Definition and Synopsis of the Etiology of Adult Gender Identity Disorder and Transsexualism. [Internet] Gender Counselor. Available from: http://www.gendercounseling.org/genderdysphoria2.html [cited 2008 Aug 24]

12. Peveller GL. Harry Benjamin Syndrome [Internet] Gender Counselor. Available from: http://www.gendercounseling.org/hbs.html [cited 2008 Sep 24]

13. Lawrence A, editor. World Professional Association for Transgender Health. The Harry Benjamin International Gender Dysphoria Association's Standards of Care For Gender Identity Disorders, Sixth Version. [Internet] Available from: http://wpath.org/Documents2/socv6.pdf [cited 2009 Apr16]

14. Gupta, R., \& Murarka, A. (2009). Treating transsexuals in India: History, prerequisites for surgery and legal issues. Indian J Plast Surg, 42(2), 226-233. doi: 10.4103/09700358.59287

15. Shah AK. In reply to topic "Gender Reassignment" Available from E mail: plastic_surgery@yahoogroups.com, on [2009 Apr 22]

16. Peveller GL. Harry Benjamin Syndrome [Internet] Gender Counselor. Available from: http://www.gendercounseling.org/hbs.html [cited 2008 Sep 24]

17. de Visser E. Wrong Body They have that 'pecker'. [Internet] Volkskrant Magazine. 2003. Sep 13, Available from: http://ai.eecs.umich.edu/people/conway/TS/Netherlands/ Wrong \% 20Body. [cited 2009 May 29]

18. Kissane K. Court lets girl, 17, remove breasts. [Internet] The Age. 2009. May 4, Available from:http://www.theage.com.au/national/court2009/05/03-arem. [cited 2009 May 29]
19. Erande RU. Sex change Operation and its legal consequences. [Internet] The Practical Lawyer. 2007. Dec 9, Available from: http://www.ebcindia.com/practicallawyer/index.ph p [cited 2009 May 25] 